\title{
Health and Social Problems associated with Prescription Opioid Misuse among a Diverse Sample of Substance-Using MSM
}

\author{
Mance E. Buttram \\ Nova Southeastern University, mance.buttram@nova.edu \\ Steven P. Kurtz \\ Nova Southeastern University, steven.kurtz@nova.edu \\ Hilary L. Surratt \\ Nova Southeastern University, surratt@nova.edu \\ Maria A. Levi-Minzi \\ Nova Southeastern University, maria.leviminzi@nova.edu
}

Follow this and additional works at: https://nsuworks.nova.edu/shss_facarticles

Part of the Medicine and Health Sciences Commons, and the Sociology Commons

\section{NSUWorks Citation}

Buttram, M. E., Kurtz, S. P., Surratt, H. L., \& Levi-Minzi, M. A. (2013). Health and Social Problems associated with Prescription Opioid Misuse among a Diverse Sample of Substance-Using MSM. Substance Use \& Misuse, 49 (3), 277-284. https://doi.org/10.3109/10826084.2013.828754

This Article is brought to you for free and open access by the Faculty Scholarship at NSUWorks. It has been accepted for inclusion in CAHSS Faculty Articles by an authorized administrator of NSUWorks. For more information, please contact nsuworks@nova.edu. 


\title{
Substance Use \& Misuse
}

\section{Health and Social Problems Associated With Prescription Opioid Misuse Among a Diverse Sample of Substance-Using MSM}

\author{
Mance E. Buttram, Steven P. Kurtz, Hilary L. Surratt \& Maria A. Levi-Minzi
}

To cite this article: Mance E. Buttram, Steven P. Kurtz, Hilary L. Surratt \& Maria A. LeviMinzi (2014) Health and Social Problems Associated With Prescription Opioid Misuse Among a Diverse Sample of Substance-Using MSM, Substance Use \& Misuse, 49:3, 277-284, DOI: 10.3109/10826084.2013.828754

To link to this article: https://doi.org/10.3109/10826084.2013.828754

Published online: 23 Aug 2013.

Submit your article to this journal ๘

Lll Article views: 275

Q View related articles $\sqsubset$

View Crossmark data

Citing articles: 10 View citing articles 


\title{
Health and Social Problems Associated With Prescription Opioid Misuse Among a Diverse Sample of Substance-Using MSM
}

\author{
Mance E. Buttram, Steven P. Kurtz, Hilary L. Surratt and Maria A. Levi-Minzi \\ Center for Applied Research on Substance Use and Health Disparities, Nova Southeastern University, Miami, \\ Florida, USA
}

\begin{abstract}
This study examines associations between prescription opioid misuse and demographics, substance use, sexual behavior, and related health and social problems. Baseline data were collected between 2008 and 2010 from 515 high risk men who have sex with men, ages 18-55, in the Miami-Ft. Lauderdale metropolitan area who reported heavy substance use and HIV risk in the past 90 days. Prescription opioid misuse was associated with other substance use, drug injection, substance dependence, and history of arrest. Implications, limitations, and directions for future study are discussed.
\end{abstract}

Keywords Prescription drugs, opioid, MSM, substance use

\section{INTRODUCTION}

Evidence suggests that men who have sex with men (MSM) are more likely to misuse prescription drugs (Kelly \& Parsons, 2013) and are more likely to experience problems suggestive of substance dependence (MackesyAmiti, Fendrich, \& Johnson, 2009) than adults in the general population. However, most research on prescription drug misuse among MSM is focused on either the misuse of erectile dysfunction medications (Kim, Kent, \& Klausner, 2002; Mansergh et al., 2006; Sherr, Bolding, Maguire, \& Elford, 2000) or the misuse of prescription drugs in general (Benotsch, Martin, Koester, Cejka, \& Luckman, 2011; Kelly \& Parsons, 2010, 2013; Mackesy-Amiti et al., 2009; Mackesy-Amiti, Fendrich, \& Johnson, 2010). Among the latter is evidence of increased sexual risk behavior among MSM who misuse prescription drugs, compared to MSM who do not (Benotsch et al., 2011; Kelly \& Parsons, 2013).

While not specific to MSM, research finds that the misuse of prescription drugs is associated with the use of a variety of additional substances (Lankenau, Schrager, et al., 2012; Wu, Woody, Yang, \& Blazer, 2012). Mul- tidrug use, including prescription drugs, has also been evidenced among MSM, where prescription drug misusers were significantly more likely to report recent use of other drugs including cocaine, ecstasy, methamphetamine, and heroin, in addition to increased sexual risk behavior (Benotsch et al., 2011). Perhaps the most alarming finding from that study was that opioid analgesics were the most commonly misused prescription drug (Benotsch et al., 2011). Prescription opioids are Schedule II controlled substances with high abuse potential (Wu et al., 2012), are highly addictive (SAMHSA, 2006), and are the class of drug most often associated with drug mortality (Benotsch et al., 2011). Kelly and Parsons (2013) found that about $11 \%$ of prescription drug misusing MSM reported recent use of pain killers. Further, a study of methamphetamine-using MSM, found that $4.2 \%$ of participants also reported misusing the prescription opioid, OxyContin ${ }^{\circledR}$ (Halkitis, Moeller, Siconolfi, Jerome, \& Rogers, 2008). To date, these are the only apparent articles in the literature that describe prescription opioid misuse among MSM, even though the misuse of prescription opioids in the United States has been escalating since the early 1990s (SAMHSA, 2012; SAMHSA, 2011).

Much of the literature examining health and social disparities among MSM suggests that greater rates of substance use (Cochran \& Mays, 2008), arrest history (Kurtz, 2008), victimization (Herek \& Sims, 2008; Purcell, Patterson, \& Spikes, 2008), and mental distress (Cochran \& Mays, 2008; Mills et al., 2004) are present among this population compared to other men. Moreover, many of these health and social problems have been found to be associated with the misuse of prescription opioids as well. Samples of chronic pain patients, street-based substance users, MSM, and opioid-dependent treatment clients report problems related to mental distress (Cicero, Surratt, Kurtz, Ellis, \& Inciardi, 2012; Pergolizzi et al., 2012), other substance abuse (Cicero et al., 2011; Cicero

Address correspondence to Mance E. Buttram, MA, Center for Applied Research on Substance Use and Health Disparities, Nova Southeastern University, 2 NE 40th Street, Miami, FL 33137, USA; E-mail: mance.buttram@ nova.edu. 
et al., 2012; Pergolizzi et al., 2012), legal issues and the law (Kurtz, 2008; Pergolizzi et al., 2012), victimization (Pergolizzi et al., 2012; Surratt, Inciardi, \& Kurtz, 2006), and hepatitis A, B, or C infection (Strassels, 2009).

The growing epidemic of prescription opioid misuse and related problems can be in part attributed to increased prescribing, availability, accessibility, and accepted medical use (Hasan \& Hasan, 2011; Lankenau, Teti, et al., 2012; McCabe, Teter, \& Boyd, 2006). The National Survey of Drug Use and Health found that the numbers of new, nonmedical users of prescription opioids increased from 600,000 in 1990 to 2 million in 2010. Among individuals ages 12 and over, $17.3 \%$ reported first-time substance use with an prescription opioid in 2010 and prescription opioids had the second largest number of past year initiates following marijuana (SAMSHA, 2011). Drug Abuse Warning Network data also reflect these increases, with abuse-related emergency department visits involving prescription opioids increasing by $156 \%$ between 2004 and 2011 (Center for Behavioral Health Statistics and Quality, 2012). Similar increases are reflected in drug abuse treatment admissions data, with past year admissions for prescription opioids increasing from 360,000 in 2002 to 754,000 in 2010 (SAMSHA, 2011).

Further exacerbating the problem of prescription opioid misuse is that nonoral routes of administration have been documented in several populations (Davis \& Johnson, 2008; Havens, Walker, \& Leukefeld, 2007; McCabe, Boyd, Cranford, \& Teter, 2009; McCabe, Cranford, Boyd, \& Teter, 2007; Young, Havens, \& Leukefeld, 2010). Such alternative routes of administration, such as injection, allow for faster drug delivery and onset, creating more intensified effects and increased abuse liability (Budman, Grimes Serrano, \& Butler, 2009). Injection of prescription opioids also facilitates transmission of HIV (Surratt, Kurtz, \& Cicero, 2011). While no studies of non-oral routes of prescription drug abuse among MSM are apparent in the literature, research shows injection drug use (IDU) is not uncommon among MSM and that the most commonly injected substances are methamphetamine and cocaine (Ghanem et al., 2011; Gorman \& Carroll, 2000; Ibañez, Purcell, Stall, Parsons, \& Gómez, 2005; O'Connell et al., 2004; Semple, Strathdee, Zians, \& Patterson, 2012; Stall \& Purcell, 2000).

These findings demonstrate the need to further investigate the problem of prescription opioid misuse and related health and social problems among high risk MSM. Because literature suggests that MSM are more likely to misuse prescription drugs than other men (Kelly \& Parsons, 2013), it is not implausible that this population would also have higher rates of prescription opioid misuse than men in the general population. With this in mind, and because of the severity of health and social problems that are generally associated with prescription opioid misuse, we sought to examine predictors of prescription opioid misuse among a sample of high risk substance-using MSM in South Florida.

\section{METHODS}

Data are drawn from baseline assessments of 515 MSM participating in a risk reduction intervention trial conducted in the Miami-Ft. Lauderdale Metropolitan Area. The study is a randomized clinical trial testing the efficacy of a four-session small group discussion intervention compared to a single-session individual counseling condition, both of which are based on theories of resilience and psychological empowerment (Fergus \& Zimmerman, 2005; Zimmerman, 1995). Participants were recruited into the study between November 2008 and October 2010. Multiple recruitment methods were employed, including direct outreach, participant referral, and internet and print media. Eligible men were between the ages of 18 and 55; reported recent (past 90 days) unprotected anal intercourse (UAI) with a nonmonogamous partner(s); and met one or more of three substance use inclusion criteria: binge drinking (five or more drinks) or drug use, excluding marijuana, at least three times in the past month; or using marijuana on 20 or more days in the past month. Research protocols were approved by the University of Delaware's (predecessor institution) and Nova Southeastern University's Institutional Review Boards.

\section{Site}

The Miami-Ft. Lauderdale metropolitan area is a wellknown migration destination for MSM, with the second highest ratio of same-sex households among large metropolitan areas in the nation (Smith \& Gates, 2001, August 22). Further, Florida has been at the center of the nation's prescription opioid epidemic for the past decade, leading the nation in numbers of illegitimate pain clinics (Gillette, 2012; Hall, 2012). Prior to new legislation in 2011 designed to better control the distribution and prescribing of prescription opioids, 90 of the nation's top 100 oxycodone-purchasing doctors resided in Florida (Gillette, 2012). In addition, Miami reports the highest AIDS rates and HIV incidence in the United States (Centers for Disease Control and Prevention, 2009) and almost half (45\%) of HIV-positive MSM in a recent Miami study were unaware of their infection (CDC, 2010).

The project was housed in two field offices, one in Wilton Manors, a suburb of Ft. Lauderdale and one in Miami Beach. Each participant was screened for eligibility, followed by informed consent and enrollment and locator data collection. Men reporting HIV-negative status were also offered confidential testing. The baseline interview session was scheduled about two weeks from enrollment, so that HIV test results could be given to men who elected testing during the same visit. All interviews were conducted in private offices using computer-assisted faceto-face interviews. Participants received HIV and drug education literature, condoms, and a $\$ 50$ stipend upon completion of the baseline activities. Baseline interviews lasted about two hours. 


\section{Measures}

The primary instrumentation for the interviews was the Global Appraisal of Individual Needs (GAIN) which has eight core sections (demographics, substance use, physical health, risk behaviors, mental health, environment, legal involvement, and vocational attainment), with each containing questions on the recency of problems, breadth of symptoms, and recent health behavior frequencies in days or times (Dennis, 2006).

Substance use measures included past 90 day frequency of use of each substance, including the nonmedical use of prescription opioids, specifically asking, "In the past 90 days, how many days did you use a prescription painkiller, opioid, or analgesic not as prescribed?". Substance dependence was assessed by the endorsement of three or more of seven Diagnostic and Statistical Manual of Mental Disorders, 4th edition, revised (DSM-IVR) symptoms during the past year (e.g., needing more drug to get the same effect, experiencing withdrawal symptoms, and being unable to quit or cut down).

An extensive battery of sexual behavior questions specific to MSM included past 90 day frequencies of receptive and insertive UAI. Because study eligibility criteria included UAI during the past 90 days, sexual risk behavior measures were dichotomized at the 66th percentile to divide the sample into higher and lower risk subgroups in these analyses. Participant HIV status was assessed by self-report, and seropositivity was verified with a notice of diagnosis or antiretroviral prescription.

Mental distress was assessed using the General Mental Distress Scale, which is comprised of past year DSMIVR symptom counts for depression ( 9 items), anxiety (12 items), and somatic disorders (4 items). This scale is reducible to classifications indicating clinical significance (subclinical, moderate, and severe) (Dennis, 2006) and was further dichotomized in the analyses presented here into "severe" and "not severe." Alpha reliability coefficients for the depression, anxiety, and somaticism subscales in this study were $.822, .829$, and .706, respectively.

Victimization was assessed by affirmative responses to the following events: being attacked with a weapon or being beaten so as to cause bruises, cuts, or broken bones (physical abuse); being forced to participate in sexual acts against one's will (sexual abuse); or being made to feel very bad about oneself or one's life (emotional abuse). For analysis, we used a summary measure: any lifetime abuse vs. no abuse.

Lifetime counts of substance abuse treatment were assessed with the question, "How many times in your life have you been admitted to detox, treatment, or counseling for your use of alcohol or any drugs?" Arrest history was assessed with the question, "In your lifetime, how many times have you been arrested, charged with a crime and booked?" Health care coverage was assessed with the question, "Are your medical expenses covered by any type of insurance, court, or health program?" Drug injection history was assessed with the following question, "When was the last time (if ever) that you used a needle to inject drugs (including steroids)?"

\section{Data Analyses}

All analyses were conducted using IBM SPSS Statistics version 20. Descriptive statistics for the entire study sample were calculated for the variables of interest including demographics, substance use, sexual risk behavior, and health and social characteristics. Bivariate logistic regression models were constructed to predict recent prescription opioid misuse. Potential predictors included in the bivariate models included demographics, other drug use, sexual risk behavior, and health and social characteristics. Those measures that exhibited significant associations in the bivariate models were included in a multivariate logistic regression model.

\section{RESULTS}

Demographics and substance use characteristics of the sample are shown in Table 1 . The racially/ethnically diverse sample was $25.8 \%$ Hispanic $(N=133), 21.0 \%$ African American/Black $(N=108)$, 48.5\% Caucasian $(N=250)$, and $4.7 \%$ "other" race/ethnicity $(N=24)$. The mean age was $38.93(\mathrm{SD}=9.64)$ years. Sixteen

TABLE 1 . Description of study sample $(N=515)$

\begin{tabular}{|c|c|c|}
\hline & $N$ & $\%$ \\
\hline \multicolumn{3}{|l|}{ Race/Ethnicity } \\
\hline Hispanic & 133 & $25.8 \%$ \\
\hline African American/Caribbean & 108 & $21.0 \%$ \\
\hline Caucasian/White & 250 & $48.5 \%$ \\
\hline Other & 24 & $4.7 \%$ \\
\hline Age (mean; SD) & 38.93 & $(9.64)$ \\
\hline Education (16 or more years) & 165 & $32.0 \%$ \\
\hline Employed full-time & 134 & $26.0 \%$ \\
\hline Health care coverage & 323 & $62.7 \%$ \\
\hline \multicolumn{3}{|l|}{ Substance use (past 90 days) } \\
\hline Binge drinking & 421 & $81.7 \%$ \\
\hline Marijuana & 336 & $65.2 \%$ \\
\hline Powder cocaine & 231 & $44.9 \%$ \\
\hline Rx sedatives & 177 & $34.4 \%$ \\
\hline Methamphetamine & 132 & $25.6 \%$ \\
\hline Rx opioids & 129 & $25.0 \%$ \\
\hline Crack cocaine & 104 & $20.2 \%$ \\
\hline Ecstasy & 93 & $18.1 \%$ \\
\hline Gamma hydroxybutyrate & 72 & $14.0 \%$ \\
\hline Rx stimulants & 27 & $5.2 \%$ \\
\hline Ketamine & 15 & $2.9 \%$ \\
\hline Heroin & 15 & $2.9 \%$ \\
\hline Drug injector (past year) & 82 & $15.9 \%$ \\
\hline Drug injector (past 90 days) & 66 & $12.8 \%$ \\
\hline \multicolumn{3}{|l|}{ Sexual risk behavior (past 90 days) } \\
\hline Partners & 13.25 & $(18.58)$ \\
\hline UAI times & 22.58 & $(35.41)$ \\
\hline \multicolumn{3}{|l|}{ Health and social characteristics } \\
\hline HIV-positive & 250 & $48.5 \%$ \\
\hline Substance dependence & 320 & $62.1 \%$ \\
\hline Substance abuse treatment history & 198 & $38.4 \%$ \\
\hline Severe mental distress & 298 & $57.9 \%$ \\
\hline Victimization history & 413 & $80.2 \%$ \\
\hline Arrest history & 332 & $64.5 \%$ \\
\hline
\end{tabular}


or more years of education were reported by $32.0 \%$ $(N=165), 26.0 \%(N=134)$ reported being employed full-time, and $62.7 \%(N=323)$ had health care coverage.

Participants reported using a host of substances during the past 90 days. A majority of participants reported binge drinking $(81.7 \% ; N=421)$ and marijuana use $(65.2 \%$; $N=336$ ). The use of stimulant and club drugs was also prevalent in the sample, with participants reporting the use of powder cocaine $(44.9 \% ; N=231)$, crack cocaine $(20.2 \% ; N=104)$, methamphetamine $(25.6 \% ; N=132)$, and ecstasy $(18.1 \% ; N=93)$ in the past 90 days. Smaller numbers of participants reported the use of heroin (2.9\%; $N=15)$, and GHB $(14.0 \% ; N=72)$. The class of prescription drugs most commonly misused was sedatives (34.4\%; $N=177)$, followed by opioids $(25.0 \% ; N=129)$, and stimulants $(5.2 \% ; N=27)$. IDU during the past year $(15.9 \% ; N=82)$ and during the past 90 days $(12.8 \%$; $N=66)$ was also reported.

During the past 90 days, participants reported a mean of 13.25 (SD 18.58) sex partners and 22.58 (SD 35.41) UAI frequency. Almost half the sample $(48.5 \% ; N=250)$ reported HIV-positive serostatus. A number of men met criteria for substance dependence $(62.1 \% ; N=320)$, reported substance abuse treatment history $(38.4 \% ; N=$ 198), met criteria for severe mental distress $(57.9 \% ; N=$ $298)$, or reported victimization $(80.2 \% ; N=413)$, or arrest histories $(64.5 \% ; N=332)$.

Bivariate logistic regression models predicting recent prescription opioid misuse are shown in Table 2. No significant associations with prescription opioid misuse were found with regard to race/ethnicity or age. Past 90 day binge drinking $(\mathrm{OR}=2.938 ; 95 \% \mathrm{CI}=1.513,5.707 ; p=$ $.001)$ and the use of powder cocaine $(\mathrm{OR}=2.329 ; 95 \%$ $\mathrm{CI}=1.546,3.501 ; p<.000)$, crack cocaine $(\mathrm{OR}=1.810$; $95 \% \mathrm{CI}=1.137,2.883 ; p=.012)$, or heroin $(\mathrm{OR}=6.403$; $95 \% \mathrm{CI}=2.146,19.104 ; p=.001)$ predicted higher odds of prescription opioid misuse, as was IDU (OR $=2.023$; $95 \% \mathrm{CI}=1.175,3.483 ; p=.011)$. No measure of sexual risk behavior proved significant, nor did HIV status. However, several health and social characteristics were associated with higher odds of prescription opioid misuse, including substance dependence $(\mathrm{OR}=2.911 ; 95 \% \mathrm{CI}=$ $1.820,4.656 ; p<.000)$, prior substance abuse treatment $(\mathrm{OR}=1.932 ; 95 \% \mathrm{CI}=1.290,2.894 ; p=.001)$, severe mental distress $(\mathrm{OR}=1.718 ; 95 \% \mathrm{CI}=1.130,2.613 ; p=$ $.011)$, victimization $(\mathrm{OR}=1.860 ; 95 \% \mathrm{CI}=1.058,3.270$; $p=.031)$, and history of arrest $(\mathrm{OR}=2.289 ; 95 \% \mathrm{CI}=$ $1.444,3.629 ; p<.000)$.

Significant predictors from the bivariate logistic regression models, in addition to demographics and HIV status, were combined into a multivariate model predicting recent prescription opioid misuse, shown in Table 3. No significant associations with prescription opioid misuse were found with regard to demographics. Substance use measures of recent binge drinking ( $\mathrm{OR}=2.473 ; 95 \%$ $\mathrm{CI}=1.777,5.198 ; p=.017)$, cocaine use $(\mathrm{OR}=1.944$; $95 \% \mathrm{CI}=1.220,3.095 ; p=.005)$, and drug injection $(\mathrm{OR}=2.197 ; 95 \% \mathrm{CI}=1.119,4.312 ; p=.022)$
TABLE 2. Bivariate logistic regression models predicting past 90 day Rx opioid misuse $(N=515)$

\begin{tabular}{|c|c|c|c|}
\hline & $p$ & OR & $95 \% \mathrm{CI}$ \\
\hline \multicolumn{4}{|l|}{ Demographics } \\
\hline Hispanic & .591 & .881 & $.554,1.399$ \\
\hline African American/Black & .793 & .936 & $.571,1.534$ \\
\hline Caucasian/White & .274 & 1.250 & $.838,1.863$ \\
\hline Other race/ethnicity & .335 & .774 & $.460,1.302$ \\
\hline $\operatorname{Age}(<30$ years $)$ & .335 & .774 & $.460,1.302$ \\
\hline \multicolumn{4}{|l|}{ Drug use (past 90 days) } \\
\hline Binge drinking & .001 & 2.938 & $1.513,5.707$ \\
\hline Cocaine & .000 & 2.329 & $1.546,3.501$ \\
\hline Crack cocaine & .012 & 1.810 & $1.137,2.883$ \\
\hline Methamphetamine & .168 & 1.365 & $.877,2.125$ \\
\hline Ecstasy & .475 & 1.202 & $.726,1.990$ \\
\hline Heroin & .001 & 6.403 & $2.146,19.104$ \\
\hline Drug injection & .011 & 2.023 & $1.175,3.483$ \\
\hline \multicolumn{4}{|l|}{ Sexual risk behavior (past } \\
\hline \multicolumn{4}{|l|}{90 days) } \\
\hline Partners ${ }^{\mathrm{a}}$ & .761 & 1.067 & $.702,1.623$ \\
\hline UAI times ${ }^{\mathrm{a}}$ & .774 & .940 & $.615,1.436$ \\
\hline Insertive UAI times $^{\mathrm{a}}$ & .736 & .931 & $.613,1.413$ \\
\hline Receptive UAI times ${ }^{\mathrm{a}}$ & .141 & 1.403 & $.894,2.202$ \\
\hline \multicolumn{4}{|c|}{ Health and social characteristics } \\
\hline HIV-positive & .347 & .825 & $.553,1.232$ \\
\hline Substance dependence ${ }^{b}$ & .000 & 2.911 & $1.820,4.656$ \\
\hline $\begin{array}{l}\text { Substance abuse treatment } \\
\text { history }\end{array}$ & .001 & 1.932 & $1.290,2.894$ \\
\hline Severe mental distress ${ }^{\mathrm{b}}$ & .011 & 1.718 & $1.130,2.613$ \\
\hline Victimization history & .031 & 1.860 & $1.058,3.270$ \\
\hline Arrest history & .000 & 2.289 & $1.444,3.629$ \\
\hline
\end{tabular}

${ }^{\mathrm{a}} 66^{\text {th }}$ percentile.

${ }^{\mathrm{b}}$ Past 12 months.

predicted higher odds of prescription opioid misuse during the past 90 days. HIV-positive serostatus was associated with lower odds of prescription opioid misuse during the past 90 days. Substance dependence $(\mathrm{OR}=2.150$;

TABLE 3. Multivariate logistic regression models predicting past 90 day Rx opioid misuse $(N=515)$

\begin{tabular}{lccc}
\hline & $p$ & OR & \multicolumn{1}{c}{$95 \%$ CI } \\
\hline Hispanic & .429 & .795 & $.450,1.404$ \\
African American/Black & .129 & .624 & $.339,1.148$ \\
Other race/ethnicity $_{\text {Age (<30 years) }}$ & .201 & .448 & $.131,1.535$ \\
Binge drinking $^{\mathrm{a}}$ & .218 & .682 & $.371,1.254$ \\
Powder cocaine $^{\mathrm{a}}$ & .017 & 2.473 & $1.177,5.198$ \\
Crack cocaine $^{\mathrm{a}}$ & .005 & 1.944 & $1.220,3.095$ \\
Heroin $^{\mathrm{a}}$ & .814 & 1.075 & $.590,1.957$ \\
Drug injection $^{\mathrm{a}}$ & .126 & 2.641 & $.767,9.099$ \\
HIV-positive $_{\text {Substance dependence }^{\mathrm{b}}}$ & .022 & 2.197 & $1.119,4.312$ \\
Substance abuse treatment history $_{\text {Severe mental distress }}^{\mathrm{b}}$ & .040 & .604 & $.374, .978$ \\
Victimization history $_{\text {Arrest history }}^{.005}$ & 2.150 & $1.253,3.689$ \\
& .460 & 1.180 & $.719,1.935$ \\
\hline
\end{tabular}

${ }^{\text {a Past }} 90$ days.

${ }^{\mathrm{b}}$ Past 12 months. 
$95 \% \mathrm{CI}=1.253,3.689 ; p=.005)$ and lifetime history of arrest $(\mathrm{OR}=1.860 ; 95 \% \mathrm{CI}=1.100,3.144 ; p=.020)$ also predicted higher odds of prescription opioid misuse during the past 90 days.

\section{DISCUSSION}

Our analyses from a diverse sample of high risk substanceusing MSM showed that race/ethnicity and age were not associated with recent prescription opioid misuse. This contrasts with previous research that documents higher rates of prescription drug misuse among older MSM (Kelly \& Parsons, 2010; Mackesy-Amiti et al. 2010) and Caucasian/White individuals in populations of MSM, college students, substance abuse treatment clients, illicit drug users, and the general population (Benotsch et al., 2011; Cicero, Inciardi, \& Muñoz, 2005; Kelly \& Parsons, 2010; McCabe et al., 2006; Miller \& Greenfeld, 2004; Simoni-Wastila, Ritter, \& Strickler, 2004; Vivian, Saleheen, SInger, Navarro, \& Mirhej, 2005). This divergence may be due to a broader distribution of prescription opioid misuse among heavy drug users, like those in our sample.

Prescription opioid misuse was associated with other substance use including binge drinking, cocaine (both powder and crack), heroin, and drug injection. Though our data do not allow us to examine whether prescription opioids were used in combination with other substances, doing so is not an unexceptional practice, and in such instances it is likely that prescription opioids are used to moderate the effects of stimulant drugs (Kurtz, 2004). Polydrug use, and especially the combination of illicit and prescription drugs is a dangerous practice (Kurtz, Inciardi, Surratt, \& Cottler, 2005) and can be even more so when drugs are injected (Havens, Oser, \& Leukefeld, 2011; Lankenau, Teti, et al., 2012; Roy, Arruda, \& Bourgois, 2011; Young et al., 2010). Prescription opioid misuse was associated with recent IDU. Increased risk for $\mathrm{HIV}$ and hepatitis $\mathrm{C}$ (HCV) infection due to unsafe injection practices among prescription opioid misusers is a documented concern (Surratt et al. 2011). Such a scenario increases the risk exposure for an already vulnerable population.

In the multivariate model, recent prescription opioid misusers in our sample had lower odds of being HIVpositive. Although at odds with other research, this finding coheres with results of the bivariate logistic regression models which indicated that prescription opioid misusing MSM were not more likely to report greater numbers of sex partners or UAI frequency. Evidence demonstrates an association between the misuse of prescription drugs in general and increased sexual risk behavior among MSM (Benotsch et al., 2011; Kelly \& Parsons 2013; MackesyAmiti et al., 2010). However, these studies were conducted with community samples and a household survey, which most likely did not include high risk heavy substance-using MSM, as did our sample. Further, in ad- dition to analgesic properties, individually varying adverse effects of prescription opioids include sedation, respiratory depression, and somnolence (Angst et al., 2012). As a result, reports of increased sexual risk behavior among prescription opioid misusers are not apparent in the literature.

Though the high risk prescription opioid misusing MSM in our sample did not have higher odds of being HIV-positive, the association between recent prescription opioid misuse and IDU is worrisome. Our data highlight the need to further examine HIV and HCV risk among high risk heavy substance-using MSM, in order to better elucidate specific risk factors for HIV transmission related to both sexual risk behavior and IDU. In the meantime, HIV and HCV prevention and intervention initiatives should be directed toward all high risk MSM, especially those who report alternate routes of administration of prescription opioids, such as injection.

MSM in our sample reporting recent prescription opioid misuse did have higher odds of reporting substance dependence, substance abuse treatment history, severe mental distress, and social risks such as histories of victimization and arrest than men who did not misuse prescription opioids. These findings reveal that even among heavy substance-using MSM, those who misuse prescription opioids are more likely to experience a host of additional health and social problems than MSM who do not misuse prescription opioids. This finding is important because, while substance use in general is associated with many risk factors, the odds of experiencing some of these health and social problems is greatly increased with the misuse of prescription opioids. Conversely, high risk MSM with health and social problems may misuse prescription opioids as a means of self-medication or as a coping behavior. Regardless of the interpretation, the association between prescription opioid misuse and elevated health and social problems among high risk substanceusing MSM is a valuable addition to the public health literature. These findings directly respond to observations that targeted and appropriate responses to prescription opioid misuse require an understanding of both the reasons for this public health problem and the unique patterns of prescription opioid misuse among specific populations (Gilson, Ryan, Joranson, \& Dahl, 2004; Surratt et al., 2006).

These results should be viewed within the context of several limitations. Although the recruitment procedures resulted in a sample of a wide age range and broadly inclusive of the racial/ethnic makeup of South Florida, our ability to generalize the findings to other MSM is limited by the study eligibility requirements, including regular substance use and recent UAI. We also note that all data are based on self-report, potentially leading to underreporting of socially undesirable behaviors. Given the high levels of substance use and sexual risk behaviors we found, however, underreporting of these and other stigmatized behaviors would appear to be 
uncommon. Finally, the cross-sectional nature of the data limits our ability to make causal inferences among the key variables.

\section{CONCLUSION}

This is the first research report to specifically investigate prescription opioid misuse among high risk MSM. While several studies have investigated prescription drug misuse among MSM, they have largely found associations with sexual risk behavior (Benotsch et al., 2011; Kelly $\&$ Parsons, 2013). Our findings advance this research and demonstrate that a host of other risk factors related specifically to prescription opioid misuse. While we found no evidence of increased sexual risk behavior among recent prescription opioid misusers in our sample, data from this study suggest that men who binge drink and/or use cocaine are more likely to misuse prescription opioids. Risks related to substance dependence and drug injection could lead to additional health problems for these men, with some of the most dangerous and immediate risks being the development of prescription opioid addiction, experiencing dangerous interactions between several substances, drug overdose or death, and HIV and HCV infection (Benotsch et al., 2011; Cai, Crane, Poneleit, \& Paulozzi, 2010; CDC, 2012; Hagan, Thiede, \& Des Jarlais, 2004; Miller et al., 2002; Paulozzi, Budnitz, \& Xi, 2006).

Because literature suggests that MSM are more likely to misuse prescription drugs than other men, it would appear likely that prescription opioid misuse among this population is a growing problem. Given the dangers of prescription opioid misuse and the alarming number of past year initiates (CBHSQ, 2012), especially among young people (SAMHSA, 2011), more attention should be paid to this public health crisis. Health care providers, especially those who serve MSM, are encouraged to inquire about patient misuse of prescription opioids and related health and social problems. Moreover, physicians prescribing opioids should engage in careful patient monitoring and frequent reassessment of risk factors (Pergolizzi et al., 2012), especially for heavy substance-using MSM. Risk reduction, mental health, and case management interventions are needed to address the misuse of prescription opioids, the use of other drugs and IDU, as wells as social risks, such as victimization and arrest history. Future research should investigate the initiation of prescription opioid misuse among MSM in order to bolster education and prevention efforts in this population.

\section{Declaration of Interest}

The authors report no conflicts of interest. The content is solely the responsibility of the authors and does not necessarily represent the official views of the National Institute on Drug Abuse or the National Institutes of Health.

This research was supported by DHHS Grant Number 5 R01 DA024579 from the National Institute on Drug Abuse.

\section{THE AUTHORS}

Mance E. Buttram, MA, is an Associate Scientist at the Center for Applied Research on Substance Use and Health Disparities at Nova Southeastern University. His primary research interests are prescription drug abuse, social relationships and communities, and resilience among vulnerable populations. In his current role, Mr. Buttram serves as Co-Investigator for a NIDA-funded randomized controlled trial of a behavioral intervention for MSM, as well as Co-Investigator and Project Director for a NIDA-funded randomized controlled trial of a self-assessment intervention for young adult club drug users.

Steven P. Kurtz, PhD, is Professor and Director of ARSH, the Center for Applied Research on Substance Use and Health Disparities at Nova Southeastern University. His research interests include prescription and illicit substance abuse, HIV risk behaviors, and related health and social problems. Dr. Kurtz is currently conducting two randomized clinical trials to test the efficacy of novel substance use and sexual risk reduction interventions designed for men who have sex with men and for young adult polydrug users in the club scene.

Hilary L. Surratt has expertise in the areas of illicit and prescription drug abuse, prescription drug diversion, and drug-related HIV infection. Her work has included the development and evaluation of HIV interventions for vulnerable populations, including criminal offenders, women drug abusers and female sex workers. She has served as PI or Co-Investigator on more than 10 NIDA-funded studies; currently she is the Principal Investigator of a NIDA-funded epidemiologic study of antiretroviral medication diversion among HIV positive substance abusers in Miami, Florida; Principal Investigator of a NIDA-funded case management intervention program for African American women at high risk for HIV; and Co-Investigator on two $\mathrm{NIH}$-funded studies targeting prescription drug abuse and the diversion of prescription drugs to the illicit market. Dr. Surratt also has substantial experience with cross-cultural research, having previously served as a senior investigator on several HIV prevention/intervention initiatives in Brazil and the U.S. Virgin Islands.

Maria A. Levi-Minzi, M.A. is a Senior Research Associate at the Center for Applied Research on Substance Use and Health Disparities at Nova Southeastern University. Her major research interests encompass the application systemic perspectives to substance abuse, victimization, and major mental illness; participant/client engagement in HIV prevention/ intervention initiatives; and social justice for marginalized populations.

\section{GLOSSARY}

Prescription opioid misuse: Defined as the nonmedical use of a prescription painkiller, opioid, or analgesic, not as prescribed. This can include using more than prescribed or using without a prescription.

\section{REFERENCES}

Angst, M. S., Lazzeroni, L. C., Phillips, N. G., Drover, D. R., Tingle, M., Ray, A., et al. (2012). Aversive and reinforcing opioid effects: A pharmacogenomic twin study. Anesthesiology, 117(1), 22-37. 
Benotsch, E. G., Martin, A. M., Koester, S., Cejka, A., \& Luckman, D. (2011). Nonmedical use of prescription drugs and HIV risk behavior in gay and bisexual men. Sexually Transmitted Diseases, 38(2), 105-110.

Budman, S. H., Grimes Serrano, J. M., \& Butler, S. F. (2009). Can abuse deterrent formulations make a difference? Expectation and speculation. Harm Reduction Journal, 6(8), 1-7.

Cai, R., Crane, E., Poneleit, K., \& Paulozzi, L. (2010). Emergency department visits involving nonmedical use of selected prescription drugs in the United States, 2004-2008. Journal of Pain and Palliative Care Pharmacotherapy, 24(3), 293-297.

Center for Behavioral Health Statistics and Quality. (2012). The DAWN report: Highlights of the 2010 drug abuse warning network (DAWN) findings on drug-related emergency department visits. Rockville, MD: Substance Abuse and Mental Health Services Administration.

Centers for Disease Control and Prevention. (2009). Table 17. Reported AIDS cases and annual rates (per 100,00 population) by metropolitan statistical area of residence, 2006, 2007, and cumulative- United States and Puerto Rico. Retrieved August 27, 2009, from http://www.cdc.gov/hiv/topics/surveillance/ resources/reports/2007report/table17.htm

Centers for Disease Control and Prevention. (2010). Prevalence and awareness of HIV infection among men who have sex with men: 21 cities, United States, 2008. Morbidity and Mortality Weekly Report, 59, 1201-1207.

Centers for Disease Control and Prevention. (2012). HIV infection and HIV-associated behaviors among injecting drug users- 20 cities, United States, 2009. Morbidity and Mortality Weekly Report, 61(8), 133-138.

Cicero, T. J., Inciardi, J. A., \& Muñoz, A. (2005). Trends in abuse of Oxycontin ${ }^{\circledR}$ and other opioid analgesics in the United States: 2002-2004. Pain, 6(10), 662-672.

Cicero, T. J., Kurtz, S. P., Surratt, H. L., Ibanez, G. I., Ellis, M. S., \& Levi-Minzi, M. A. (2011). Multiple determinants of specific modes of prescription opioid diversion. Journal of Drug Issues, 41(2), 283-304. doi: 0022-0426/11/01

Cicero, T. J., Surratt, H. L., Kurtz, S. P., Ellis, M. S., \& Inciardi, J. A. (2012). Patterns of prescription opioid abuse and co-morbidity in an aging treatment populations. Journal of Substance Abuse Treatment, 42(1), 87-94.

Cochran, S. D., \& Mays, V. M. (2008). Prevalence of primary mental health morbidity and suicide symptoms among gay and bisexual men. In R. Wolitski, R. Stall \& R. O. Valdiserri (Eds.), Unequal opportunity: Health disparities affecting gay and bisexual men in the United States. New York: Oxford University Press.

Davis, W. R., \& Johnson, B. D. (2008). Prescription opioid use, misuse, and diversion among street drug users in New York City. Drug and Alcohol Dependence, 92(1-3), 1-17.

Dennis, M. L. (2006). Global appraisal of individual needs. Version 5.4. Bloomington, IL: Chestnut Health Systems.

Fergus, S., \& Zimmerman, M. A. (2005). Adolescent resilience: A framework for understanding health development in the face of risk. Annual Review of Public Health, 26, 399-419.

Ghanem, A., Little, S. J., Drumright, L., Liu, L., Morris, S., \& Garfein, R. S. (2011). High-risk behaviors associated with injection drug use among recently hiv-infected men who have sex with men in San Diego, CA. AIDS and Behavior, 15(7), 15611569.

Gillette, F. (2012). American pain: The largest U.S. Pill mill's rise and fall. Bloomberg Businessweek. http://www.businessweek. com/articles/2012-06-06/american-pain-the-largest-u-dot-s-dotpill-mills-rise-and-fall.
Gilson, A. M., Ryan, K. M., Joranson, D. E., \& Dahl, J. L. (2004). A reassessment of trends in the medical use and abuse of opioid analgesics and implications for diversion control: 1997-2002. Journal of Pain and Symptom Management, 28(2), 176-188.

Gorman, E. M., \& Carroll, R. T. (2000). Substance abuse and HIV: Considerations with regard to methamphetamines and other recreational drugs for nursing practice and research. Journal of the Association of Nurses in AIDS Care, 11(2), 51-62.

Hagan, H., Thiede, H., \& Des Jarlais, D. C. (2004). Hepatits C virus infection among injection drug users: Survival analysis of time to seroconversion. Epidemiology, 15(5), 543-549. doi: 10.1097/01.ede.0000135170.54913.9d

Halkitis, P. N., Moeller, R. W., Siconolfi, D. E., Jerome, R. C., \& Rogers, M. M. (2008). Methamphetamine and poly-substance use among gym-attending men who have sex with men in New York City. Annals of Behavioral Medicine, 35(1), 41-48.

Hall, J. N. (2012). Drug abuse trends in Miami-Dade and Broward counties, South Florida. Paper presented at the Community and Epidemiology Work Group. June 8-11. Palm Springs, CA.

Hasan, M. K., \& Hasan, O. K. (2011). Opiate addiction and prescription drug abuse: A pragmatic approach. Journal of the Islamic Medical Association of North America, 43, 23-26.

Havens, J. R., Oser, C. B., \& Leukefeld, C. G. (2011). Injection risk behaviors among rural drug users: Implications for HIV prevention. AIDS Care, 25(5), 638-645. doi: 10.1080/09540121. 2010.516346

Havens, J. R., Walker, R., \& Leukefeld, C. G. (2007). Prevalence of opioid analgesic injection among rural nonmedical opioid analgesic users. Drug and Alcohol Dependence, 87, 98-102. doi: 10.1016/j.drugalcdep.2006.07.008

Herek, G. M., \& Sims, C. (2008). Sexual orientation and violent victimization: Hate crimes and intimate partner violence among gay and bisexual males in the united states. In R. Wolitski, R. Stall \& R. O. Valdiserri (Eds.), Unequal opportunity: Health disparities affecting gay and bisexual men in the United States. (pp. 35-71). New York: Oxford University Press, Inc.

Ibañez, G. E., Purcell, D. W., Stall, R., Parsons, J. T., \& Gómez, C. A. (2005). Sexual risk, substance use, and psychological distress in HIV-positive gay and bisexual men who also inject drugs. AIDS, 19(Suppl 1), S49-S55.

Kelly, B. C., \& Parsons, J. T. (2010). Prevalence and predictors of non-medical prescription drug use among men who have sex with men. Addictive Behaviors, 35(4), 312-317.

Kelly, B. C., \& Parsons, J. T. (2013). Prescription drug misuse and sexual risk taking among HIV-negative MSM. AIDS and Behavior, 17(3), 926-930. doi: 10.1007/s10461-011-9993-z

Kim, A. A., Kent, C. K., \& Klausner, J. D. (2002). Increased risk of HIV and sexually transmitted disease transmission among gay or bisexual men who use Viagra, San Francisco 2000-2001. AIDS, 16(10), 1425-1428.

Kurtz, S. P. (2004). Prescription drug abuse among ecstasy users in Miami: Qualitative research findings. Epidemiologic trends in drug abuse, advance report: Prescription Drug Abuse Community Epidemiology Work Group, June 2004. (pp. 43-47). NIH Publication No. 04-5363A, Rockville, MD, The Institute, November 2004.

Kurtz, S. P. (2008). Arrest histories of high risk gay and bisexual men in Miami: Unexpected additional evidence for syndemic theory. Journal of Psychoactive Drugs, 40(4), 513-521.

Kurtz, S. P., Inciardi, J. A., Surratt, H. L., \& Cottler, L. (2005). Prescription drug abuse among ecstasy users in Miami. Journal of Addictive Diseases, 24(4), 1-16.

Lankenau, S. E., Schrager, S. M., Silva, K., Kecojevic, A., Bloom, J. J., \& Wong, C. (2012). Misuse of prescription and illicit drugs 
among high-risk young adults in Los Angeles and New York. Journal of Public Health Research, 1(1), 22-30.

Lankenau, S. E., Teti, M., Silva, K., Bloom, J. J., Harocopos, A., \& Treese, M. (2012). Initiation into prescription opioid misuse amongst young injection drug users. International Journal of Drug Policy, 23(1), 37-44. doi: 10.1016/ j.drugpo.2011.05.014

Mackesy-Amiti, M. E., Fendrich, M., \& Johnson, T. P. (2009). Substance-related problems and treatment among men who have sex with men in comparison to other men in Chicago. Journal of Substance Abuse Treatment, 36(2), 227-233.

Mackesy-Amiti, M. E., Fendrich, M., \& Johnson, T. P. (2010). Symptoms of substance dependence and risky sexual behavior in a probability sample of HIV-negative men who have sex with men in Chicago. Drug and Alcohol Dependence, 110(1-2), 38-43.

Mansergh, G., Shouse, R. L., Marks, G., Guzman, R., Rader, M., $\&$ Buchbinder, S. (2006). Methamphetamine and sildenafil (Viagra) use are linked to unprotected receptive and insertive anal sex, respectively, in a sample of men who have sex with men. Sexually Transmitted Infections, 82(2), 131-134.

McCabe, S. E., Boyd, C. J., Cranford, J. A., \& Teter, C. J. (2009). Motives for non-medical use of prescription opioids among high school seniors in the United States: Self treatment and beyond. Archives of Pediatric and Adolescent Medicine, 163(8), 739-744.

McCabe, S. E., Cranford, J. A., Boyd, C. J., \& Teter, C. J. (2007). Motives, diversion, and routes of administration associated with nonmedical use of prescription opioids. Addictive Behaviors, 32, 562-575.

McCabe, S. E., Teter, C. J., \& Boyd, C. (2006). Medical use, illicit use, and diversion of abusable prescription drugs. Journal of American College Health, 54(5), 269-278.

Miller, C. L., Johnston, C., Spittal, P. M., Li, K., LaLiberte, N., Montaner, J. S. G., et al. (2002). Opportunities for prevention: Hepatitis $\mathrm{C}$ prevalence and incidence in a cohort of young injection drug users. Hepatology, 36(3), 737-742. doi: 10.1053/jhep.2002.35065

Miller, N. S., \& Greenfeld, A. (2004). Patient characteristics and risks factors for development of dependence on hydrocodone and oxycodone. American Journal of Therapeutics, 11(1), 26-32.

Mills, T. C., Paul, J., Stall, R., Pollack, L., Canchola, J., \& Chang, Y. J. (2004). Distress and depression in men who have sex with men: The Urban Men's Health Study. American Journal of Psychiatry, 161(2), 278-285.

O'Connell, J. M., Lampinen, T. M., Weber, A. E., Chan, K., Miller, M. L., \& Schechter, M. T. (2004). Sexual risk profile of young men in Vancouver, British Columbia, who have sex with men and inject drugs. AIDS and Behavior, 8(1), 17-23.

Paulozzi, L. J., Budnitz, D. S., \& Xi, Y. (2006). Increasing deaths from opioid analgesics in the United States. Pharmacoepidemiology and Drug Safety, 15(9), 618-627.

Pergolizzi Jr., J. V., Gharibo, C., Passik, S., Labhsetwar, S., Taylor Jr., R., \& Pergolizzi, J. S. (2012). Dynamic risk factors in the misuse of opioid analgesics. Journal of Psychosomatic Research, 72, 443-451.

Purcell, D., Patterson, J. D., \& Spikes, P. S., Jr. (2008). Childhood sexual abuse experienced by gay and bisexual men: Understanding the disparities and interventions to help eliminate them. In R. Wolitski, R. Stall \& R. O. Valdiserri (Eds.), Unequal oppor- tunity: Health disparities affecting gay and bisexual men in the United States. (pp. 72-96). New York: Oxford University Press.

Roy, E., Arruda, N., \& Bourgois, P. (2011). The growing popularity of prescription opioid injection in downtown Montreal: New challenges for harm reduction. Substance Use and Misuse, 46(9), 1142-1150.

Semple, S. J., Strathdee, S. A., Zians, J., \& Patterson, T. L. (2012). Factors associated with experiences of stigma in a sample of hivpositive, methamphetamine-using men who have sex with men. Drug and Alcohol Dependence, 125(1-2), 154-159.

Sherr, L., Bolding, G., Maguire, M., \& Elford, J. (2000). Viagra use and sexual risk behaviour among gay men in London. AIDS, 14(13), 2051-2053.

Simoni-Wastila, L., Ritter, G., \& Strickler, G. (2004). Gender and other factors associated with the nonmedical use of abusable prescription drugs. Substance Use and Misuse, 39(1), 1-23.

Smith, D. M., \& Gates, G. J. (2001, August 22). Gay and lesbian families in the united states: Same-sex unmarried partner households: A preliminary analysis of 2000 United States census data, a Human Rights Campaign report. Washington, DC: Human Rights Campaign.

Stall, R. D., \& Purcell, D. W. (2000). Intertwining epidemics: A review of research on substance use among men who have sex with men and its connection to the AIDS epidemic. AIDS and Behavior, 4(2), 181-192.

Strassels, S. A. (2009). Economic burden of prescription opioid misuse and abuse. Journal of Managed Care Pharmacy, 15(7), 556-562.

Substance Abuse and Mental Health Services Administration. (2012). Results from the 2011 National Survey on Drug Use and Health: Summary of national findings. NSDUH series H44, HHS publication no. (SMA) 12-4713. Rockville, MD: Substance Abuse and Mental Health Services Administration.

Substance Abuse and Mental Health Services Administration. (2006). Prescription medications: Misuse, abuse, depdencend, and addiction. Substance Abuse Treatment Advisory, 5(2), 1-4.

Substance Abuse and Mental Health Services Administration. (2011). Results from the 2010 National Survey on Drug Use and Health: Summary of national findings. NSDUH Series H41, HHS Publication No. (SMA) 11-4658. Rockville, MD: Substance Abuse and Mental Health Services Administration.

Surratt, H. L., Inciardi, J. A., \& Kurtz, S. P. (2006). Prescription opioid abuse among drug-involved street-based sex workers. Journal of Opioid Management, 2(5), 283-289.

Surratt, H. L., Kurtz, S. P. \& Cicero, T. J. (2011) Alternate routes of administration and risk for HIV among prescription opioid abusers. Journal of Addictive Diseases, 30(4), 334-341.

Vivian, J., Saleheen, H., SInger, M., Navarro, J., \& Mirhej, G. (2005). Under the counter: The diffusion of narcotic analgesics to the inner city street. Journal of Ethnicity in Substance Abuse, 4(2), 97-114.

Wu, L.-T., Woody, G. E., Yang, C., \& Blazer, D. G. (2012). Subtypes of nonmedical opioid users: Results from the national epidemiologic survey on alcohol and related conditions. Drug and Alcohol Dependence, 112(1-2), 69-80.

Young, A. M., Havens, J. R., \& Leukefeld, C. G. (2010). Route of administration for illicit prescription opioids: A comparison of rural and urban drug users. Harm Reduction Journal, 7(24), 1-7.

Zimmerman, M. A. (1995). Psychological empowerment: Issues and illustrations. American Journal of Community Psychology, 23(5), 581-599. 